\title{
Switch to large pictorial health warnings on cigarette packs
}

During the editing of this Letter by George Thomson and colleagues (BMJ 2013;346:f2084, doi:10.1136/bmj.f2084) we altered the intended meaning of the authors' original phrasing explaining the pictorial health warnings on cigarette packs. In the third paragraph the first sentence should have started: "In the meantime, New Zealand has a pictorial health warning that covers $30 \%$ of the area on the front of packs [not "on the front of $30 \%$ of packs"]..."

Cite this as: BMJ 2013;346:f2358

๑ BMJ Publishing Group Ltd 2013 